\title{
The role of pharmacology in anticancer drug development
}

\author{
Godefridus J. Peters ${ }^{1, *}$, Anne-Sophie Govaerts ${ }^{2}$, Hans R Hendriks ${ }^{3}$, for the EORTC- \\ Pharmacology and Molecular Mechanism Group \\ ${ }^{1}$ Dept of Medical Oncology, VU University Medical Center, PO Box 7057, 1007 MB Amsterdam, The Netherlands \\ ${ }^{2}$ EORTC, Avenue E. Mounier 83/11, 1200 Brussels, Belgium \\ ${ }^{3}$ Hendriks Pharmaceutical Consulting, J. Wagenaarstraat 67, 1443 LR Purmerend, The Netherlands \\ *Corresponding Author: E-mail: gj.peters@vumc.nl
}

Received: January 11, 2018; Revised: March 07, 2018; Published: March 25, 2018

\begin{abstract}
Drug development consists of many sequential and parallel steps; failure in one of the steps can lead to discontinuation of the process. The process is time-consuming and very expensive, especially the clinical phase. In order to enhance cancer drug development in the 1980s, the National Cancer Institute (NCI) adopted a new screening system using 60 different tumour cell lines from various histologies. All standard drugs were tested in this panel and it is still open for testing of new chemical entities (NCE) of potential interest. The European $\mathrm{NCl}$ compounds initiative, a collaborative programme of the $\mathrm{NCl}$, the Cancer Research Campaign (CRC; now CRUK) and the Pharmacology and Molecular Mechanism Group (PAMM) of the EORTC (European Organization on Research and Treatment of Cancer), was initiated in 1993. The programme aimed to help the $\mathrm{NCl}$ reducing its backlog of in vivo testing by further evaluation of interesting European compounds using a pharmacologically directed approach. Considerable multidisciplinary expertise in drug development was combined by the CRC and EORTC-PAMM: chemists, pharmacists, biologists, pharmacologists, oncologists. Selection criteria for European $\mathrm{NCl}$ compounds included novelty of the NCE, in vitro activity, if available in vivo and hollow fibre activity, and COMPARE negativity. Over a period of more than 20 years 95 out of approximately 2,000 reviewed compounds were selected. These compounds were put through a series of stepwise pharmacological tests comprising solubility (suitable formulation to administer the NCE to mice), feasibility to develop a simple analytical assay (usually HPLC), limited toxicology and angiogenic properties. This paper provides examples to illustrate the rigorousness of the elimination process of the compounds and discusses the way to improve the process by inclusion of more physico-chemical parameters.
\end{abstract}

\section{Keywords}

EORTC-PAMM; NCl; CRUK; in vitro screen; pharmacological approach; anticancer drug development; European $\mathrm{NCl}$ compounds

\section{Introduction}

Anticancer drug development is a collaborative effort. When a compound has been synthesised chemically or isolated from a specific source, e.g. a natural product, it will be characterised chemically, physically, pharmacologically, pharmaceutically, toxicologically and biologically, requiring the input from various disciplines. When a compound passes all these steps successfully it continues to clinical development [1]. A tightly controlled process precedes the first administration to a patient. This process is 
subject to many regulations and requires approval by local hospital medical ethical review boards and national competent authorities. This first step is the Phase I clinical study, in which the safety, side effects and best dose of a drug are determined. The latter can be the maximum tolerated dose (MTD) for cytotoxics or the maximum effective dose (usually lower than the MTD) for compounds affecting signaling pathways. This dose is used to determine the antitumor activity of the agent in a Phase II study [1-3]. In the classical drug development setting, an active compound (antitumor activity comparable to that of standard therapy), will proceed to a randomised Phase III study in which the new drug will be compared to the standard therapy or placebo. However, with several novel compounds in which a target is defined, a Phase I study may be expanded to include only patients with predefined biomarkers [3]. Drugs can obtain market approval from Medicines agencies such as the EMA and FDA, based on an extensive risk/benefit ratio evaluation.

An increasing understanding of cancer biology leads to a heterogeneity at multiple levels (genetic, functional, tumour components, signalling pathways), which translates into an increasing number of products in the pipeline of pharmaceutical companies. This high number of compounds resulted in more Phase I, II and III clinical trials requiring even more patients, which led to extensively high costs for pharmaceutical industry and subsequently health care in society [4,5]. These numbers (costs and number of patients) are increasing in the last decades [6], while the rate of success in oncology drug development is limited, compared to other diseases [7]. In order to keep the costs as low as possible it is important that every aspect of the development process is critically reviewed, including optimisation of drug selection at an early stage.

The European Organization for Research and Treatment of Cancer (EORTC) is the largest European organization coordinating clinical studies in the development of new cancer therapies [8]. The National Cancer Institute $(\mathrm{NCl})$ in Bethesda, MD, USA, developed in the 2 nd half of the 1980s a 60-cell line panel (called $\mathrm{NCl}-60$ panel throughout this paper), consisting of 60 cell lines representative for the 9 major tumour types, with the aim to select compounds that show selective potency against one of these malignancies [9]. This $\mathrm{NCl}-60$ panel was offered to the scientific community to test the potency of Novel Chemical Entities (NCEs) and since that period hundreds of thousands of compounds have been submitted to the $\mathrm{NCl}$ screen, but not all passed the initial $\mathrm{NCl}$ selection procedure and were not tested. Several tested compounds showed an interesting profile and were candidates for further development e.g. in vivo testing, but early in this process it was recognized that too many compounds fulfilled the criteria for in vivo testing. In order to speed up the backlog in this development and since many compounds came from Europe, an international academic collaboration between both sides of the Atlantic was initiated in 1993, between the EORTC Research Branch, the Cancer Research Campaign (CRC, now CRUK) and the $\mathrm{NCl}$, the so-called European $\mathrm{NCl}$ compounds initiative, which focused on compounds synthesised in Europe and showing interesting data in the $\mathrm{NCl}$ screen. CRC and EORTC set up a review committee to select European compounds for further development $[10,11]$. About 2,000 compounds were evaluated by the CRC-EORTC review committee in $>20$ years and $\mathbf{9 5}$ were selected for further evaluation. Further details on this process and the achievements have recently been summarised [10]. The purpose of this paper is to evaluate mechanistic details e.g. ADME (Absorption, Distribution, Metabolism, Excretion) in this process by describing the development of several compounds that either failed or were successful. Successful means moving into Phase I or eventually Phase II clinical studies. Failure may have been caused by obvious parameters, such as lack of potency, poor solubility, stability and other physico-chemical properties. 


\section{The process of European $\mathrm{NCl}$ compound evaluation}

In the early 1990s, the screening's capacity of the NCl-60 panel was 10,000 compounds annually. NCEs, submitted by scientists from all over the world, are selected for screening based on structural diversity and novelty of the compound. In the initial program selected NCEs were tested at 5 different concentrations (varying over 5 logs: $10^{-4}-10^{-8}$ or $10^{-5}-10^{-9} \mathrm{M}$ ) and cells were exposed for 48 hours to the drug. Three parameters were determined for each drug: the GI50 (or IC50: $50 \%$ growth inhibition), the TGI (total growth inhibition) and the LC50 (50\% cell kill or $50 \%$ lethal concentration) (Figure 1) [12]. The results of the screen are reported as growth inhibition curves as shown in Figure 2 for compound NSC-625492. Many current drug sensitivity tests often denote these curves as viability curves. This is not a correct terminology, because growth inhibition is measured. The $\mathrm{NCl}$ data are summarized as mean graphs for GI50, TGI or LC50 values. These mean graphs depict whether a cell line is more or less sensitive than the GI50/TGI/LC50 mean of the test drug in the $\mathrm{NCl}-60$ panel. Figure 3 shows the mean graphs of compound NSC-710305 [13], also known as Phortress, and a prodrug of Phortress 5F-203. These mean graphs demonstrate a tumour specific sensitivity for lung, ovarian, renal and breast cancer (bars to the right). Subsequent mechanistic studies were performed according to the guidelines published recently [14].

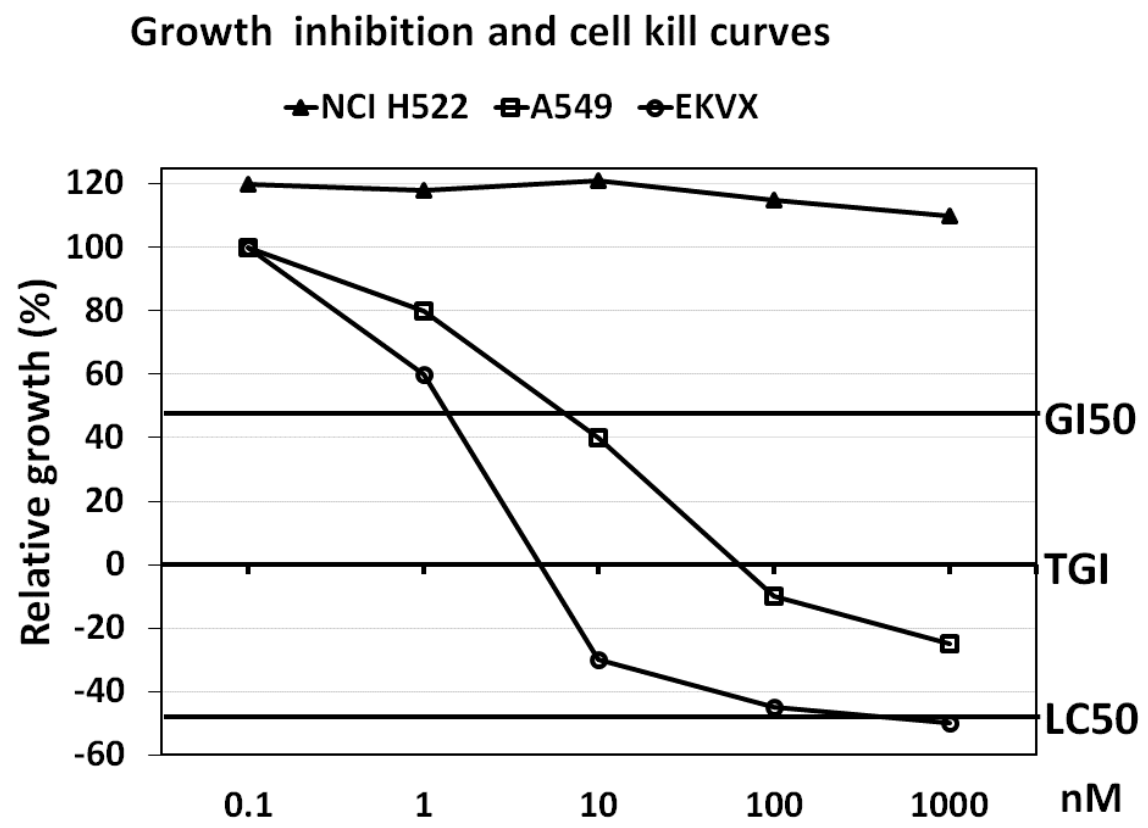

Figure 1. Example growth inhibition curves after 48 hours exposure to a hypothetical drug tested at 0.1 to $1000 \mathrm{nM}$ in three lung cancer cell lines. Three parameters are shown: the GI50 (the concentration that gives $50 \%$ growth inhibition, often also referred to as IC50), the TGI (the concentration that gives a total growth inhibition meaning that the number of cells at the end of the exposure is similar to that at the beginning) and the LC50 (the concentration that gives $50 \%$ cell kill, meaning that at the end the number of cells is $50 \%$ of the number of cells at the beginning). Values are calculated according to the $\mathrm{NCl}$ protocol: https://dtp.cancer.gov/discovery development/nci-60/methodology.htm

When positive, such as for Phortress, compounds were further screened in a human tumour xenograft (HTX) panel. However, the $\mathrm{NCl}$ screen yielded too many potential compounds for HTX testing, so that a fast low-cost preliminary in vivo screen was developed, the so-called hollow fibre assay (HFA) $[15,16]$. This assay combines advantages of in vitro screens (relatively fast, several tumour types together) and bypasses the disadvantages such as the poor predictive capacity for in vivo activity and lack of information on potential pharmacological properties. The latter are important to determine the amount of drug to be delivered [17]. The HFA appeared to predict for HTX activity $[18,19]$. 
Sensitivity to NSC-625492 in the NCl-60 cell line panel (source NCI DTP)

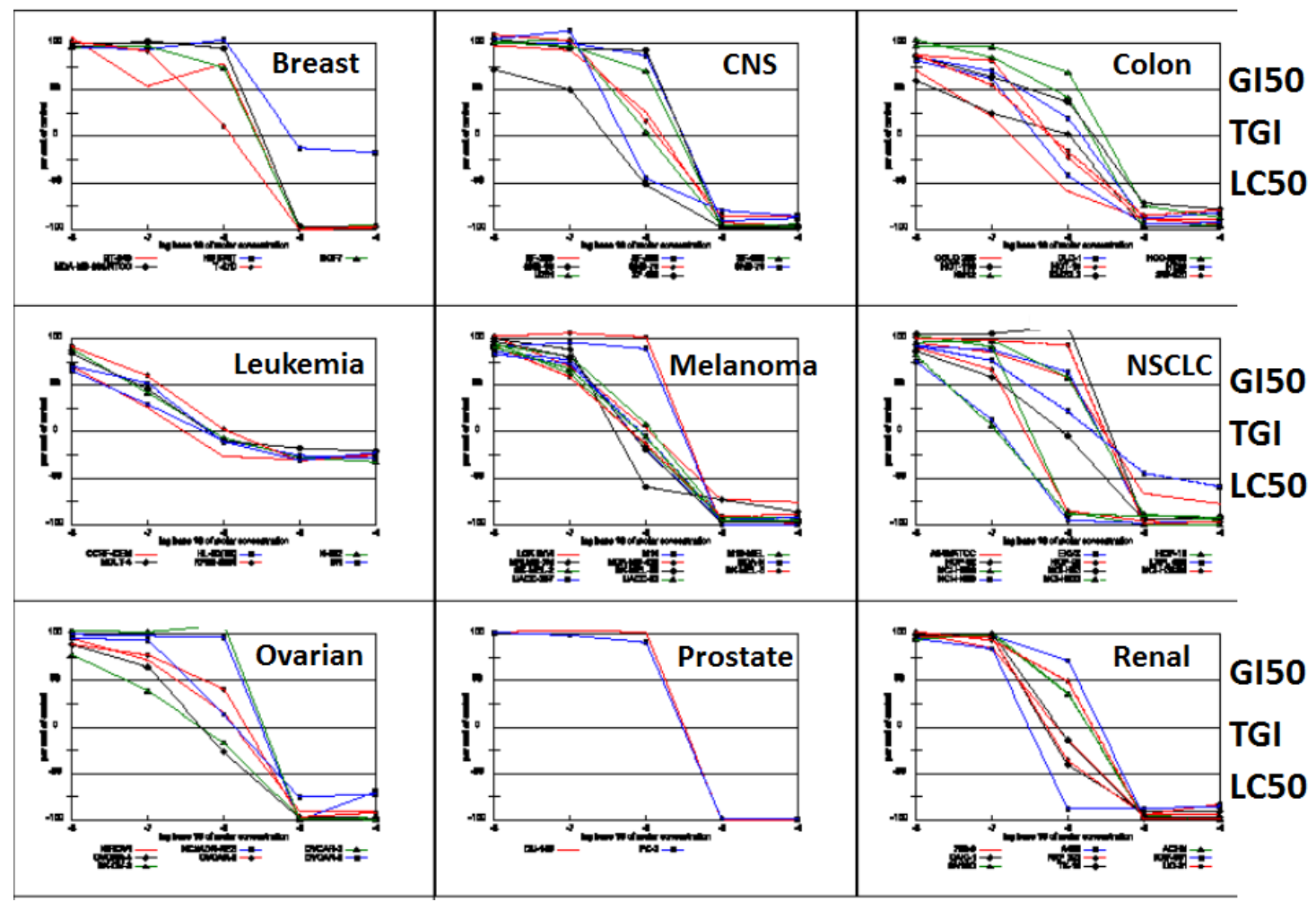

Figure 2. Example of a typical NCl-60 cell line growth inhibition report for compound NSC-625492. Each panel represents cell lines derived from of a particular type of cancer (left to right, top to bottom): 5 breast cancer cell lines), 8 central nervous system (CNS) cell lines, 9 colon cancer cell lines, 6 leukaemia cell lines, 11 melanoma cell lines, 11 non-small cell lung cancer (NSCLC) cell lines, 7 ovarian cancer cell lines (including one with P-glycoprotein overexpression), 2 prostate cancer cell lines, 9 renal cancer cell lines). The two small cell lung cancer cell lines are not shown. The compound was tested at the concentration range of $10^{-8}$ to $10^{-4} \mathrm{M}$ and cells were exposed for $48 \mathrm{hr}$. Obtained from the NCI DTP database https://dtp.cancer.gov/discovery development/nci-60/methodology.htm.

In addition to the potency of the drugs (e.g. Figure 2), the selectivity for a certain tumour type in vitro (mean graph, Figure 3), the HFA and if available the HTX data, another important selection criterion for the European $\mathrm{NCl}$ compounds were the COMPARE data [20]. COMPARE is a comparison tool developed by the $\mathrm{NCl}$ based on the sensitivity profile of an NCE compared to the whole database. COMPARE-positive compounds (Pearson correlation coefficient $\geq 0.8$ ) often showed the same mechanism of action; these compounds could be structurally related but also unrelated compounds $[9,12]$. Since COMPARE-negative compounds (Pearson correlation coefficient $<0.8$ ) usually did not have close matches in the COMPARE programme, they might have a novel mechanism of action and were thought to be most interesting.

For administration of drugs to animals often additional hurdles needed to be solved, such as the administration vehicle, which will be different from formulations used in vitro [14]. Many compounds were poorly soluble and specific formulations were used, dependent on the compound, but keeping in mind what might be suitable for future administration to patients. Hence dimethyl sulfoxide (DMSO) might be suitable for in vitro and in vivo to mice, but not for patients (Table 1). After this pre-formulation step, the potential bioavailability of a compound was investigated. After the development of a suitable HPLC assay (or another analytical assay) and using a proper formulation, the MTD in mice was determined. The MTD was administered and plasma pharmacokinetics determined at various time points to ascertain whether the drug would reach plasma concentrations in the range of the in vitro GI50. Subsequently, this dose and schedule were used to explore whether the compound would have suitable in vivo antitumor activity. If so, 
the development was continued and if not, stopped. In the next section, several examples of such a development will be presented.

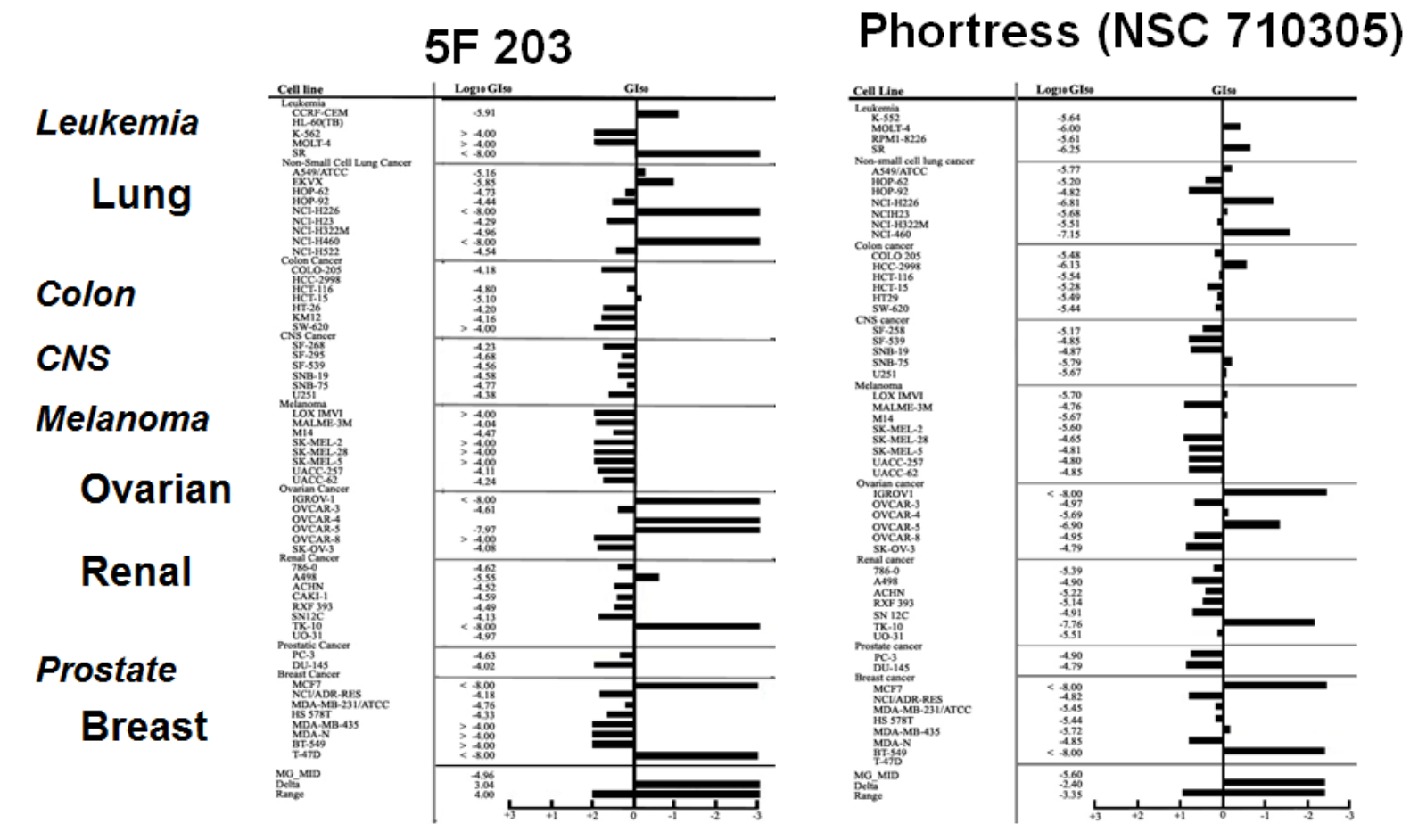

Figure 3. Example report of drug selectivity for 5F-203 and its prodrug Phortress (source NCI DTP). Values are calculated relative to the mean GI50 for each compound. Differences compared to the mean are given as a $\log 10$ value, with bars to left representing less sensitive cell lines $\left(10^{3}\right.$ to 0$)$ and those to the right more sensitive cell lines $\left(0\right.$ to $\left.10^{-3}\right)$. Cell lines from top to bottom represent 5 leukaemia cell lines, 9 NSCLC, 7 colon cancer, 6 CNS, 8 melanoma, 6 ovarian cancer, 8 renal cancer, 2 prostate cancer, 8 breast cancer (including one with P-glycoprotein overexpression). Please note that the composition of this panel is different from

Figure. 2 . The most sensitive cell lines are depicted in a larger font. The non-responsive in Italics.

\section{Examples of selected compounds}

In one of the early selected series of compounds, NSC-697786 (Figure 4) showed an interesting profile in the COMPARE analysis with a COMPARE coefficient of 0.503 for methotrexate, 0.498 for DUP785 (Brequinar), 0.496 for $\mathrm{N}$-phosphon-acetyl-L-aspartate (PALA) and 0.474 for trimetrexate. This indicates some similarity with antifolates (methotrexate and trimetrexate) and pyrimidine de novo nucleotide inhibitors (DUP785 and PALA). The standard approach to exclude this is a comparison in cell lines with aberrations in folate metabolism and to perform rescue experiments with normal pyrimidine nucleosides, respectively. Consequently, this compound was tested in colon cancer WiDr cells grown in standard culture medium (which has a high folate concentration) and WiDr cells that are adapted to a low physiological (comparable to human plasma; WiDr/F) folate concentration [21]. A similar IC50 was found in both lines ( $0.26 \pm 0.06$ and $0.25 \pm 0.07 \mu \mathrm{M}$, respectively; means \pm SE of 4-7 experiments; 72 -hour exposure). WiDr/F cells are more sensitive to antifolates such as methotrexate. Addition of 1 or $5 \mathrm{mM}$ uridine or cytidine did not protect the cells, which would have been indicative for a pyrimidine de novo inhibition [22]. FMA3 wild type and FMA3/TK- (thymidine kinase deficient) [23] were similarly sensitive (IC50 values for NSC-697786 $3.2 \pm 0.2$ and $2.0 \pm 0.8 \mu \mathrm{M}$ ), which excluded a role for thymidine kinase. It was concluded that this compound is a not acting as an antimetabolite, and had possibly unique mechanism of action. However, it was discontinued due to lack of in vivo activity, possibly because of poor pharmacokinetics. 
Table 1. Acceptable solvents for in vitro drug solutions or in vivo administration of drugs to mice or rats.

\begin{tabular}{|c|c|c|c|c|}
\hline Solvent & $\begin{array}{c}\text { Maximal } \\
\text { concentration }\end{array}$ & $\begin{array}{l}\text { Maximal } \\
\text { dose }\end{array}$ & Species & $\begin{array}{l}\text { Maximal final } \\
\text { concentration }\end{array}$ \\
\hline & In vivo & & & In vitro \\
\hline Culture medium & & & & $\begin{array}{l}\text { DMEM, RPMI } \\
\left(1^{\text {st }} \text { choice }\right)\end{array}$ \\
\hline water & & & & $10 \%$ (final) \\
\hline $0.9 \%$ Saline $\mathrm{pH} 7.4$ & & $0.5 \mathrm{ml}$ & Mice; rats & $2^{\text {nd }}$ choice \\
\hline Saline $\mathrm{pH} 2.0$ & & $0.5 \mathrm{ml}$ & Rats (dx5) & Not acceptable \\
\hline Saline pH 11 & & $0.5 \mathrm{ml}$ & Rats $(d \times 5)$ & Not acceptable \\
\hline Ethanol & $10 \%$ & $10 \mathrm{ml} / \mathrm{kg}$ & Mice (i.v.) & $1 \%$ \\
\hline \multirow{3}{*}{$\begin{array}{l}\text { Dimethylsulfoxide } \\
\text { (DMSO) }\end{array}$} & $10 \%$ in water & $10 \mathrm{ml} / \mathrm{kg}$ & Mice (i.v.; p.o.) & \multirow{4}{*}{$\begin{array}{c}0.25 \% \text { (0.1\% } \\
\text { preferable) } \\
0.125 \% \text { (upper } \\
\text { limit) }\end{array}$} \\
\hline & $1 \%$ in water & $10 \mathrm{ml} / \mathrm{kg}$ & Mice (i.p.) & \\
\hline & $70 \%$ in saline & $0.2 \mathrm{ml}$ & Rats (dx5) & \\
\hline Dimethylformamide & & & & \\
\hline \multirow{2}{*}{ Tween 80} & $10 \%$ in water & $10 \mathrm{ml} / \mathrm{kg}$ & Mice (i.v.) & \\
\hline & $25 \%$ in saline & $0.2 \mathrm{ml}$ & Rats (dx5) & \\
\hline \multirow{3}{*}{ Propylene glycol } & $50 \%$ & $10 \mathrm{ml} / \mathrm{kg}$ & Mice (i.v., slow) & \\
\hline & $25 \%$ & $10 \mathrm{ml} / \mathrm{kg}$ & Mice (i.p) & \\
\hline & $50 \% / 25 \%$ & $0.2 \mathrm{ml}$ & Rats (dx5) & \\
\hline N-methyl glucamine & $1 \%$ in water & $10 \mathrm{ml} / \mathrm{kg}$ & Mice (p.o.) & \\
\hline $\begin{array}{l}\text { Carboxymethyl } \\
\text { cellulose }\end{array}$ & $1 \%$ in water & $10 \mathrm{ml} / \mathrm{kg}$ & Mice (i.p) & \\
\hline Cremophor EL & $5 \%$ in water & $10 \mathrm{ml} / \mathrm{kg}$ & Mice (i.v.) & \\
\hline $\mathrm{NaHCO} 3$ & $5 \%$ in water & $10 \mathrm{ml} / \mathrm{kg}$ & Mice (i.v.) & \\
\hline $\begin{array}{l}\text { N,N-Dimethyl- } \\
\text { acetamide (DMA) }\end{array}$ & $10 \%$ in water & $10 \mathrm{ml} / \mathrm{kg}$ & Mice (i.p.) & \\
\hline DMA & $10 \%$ in arachis oil & $10 \mathrm{ml} / \mathrm{kg}$ & Mice (i.p.) & \\
\hline
\end{tabular}

Guidelines developed by the Joint Formulation Working party of the Screening and Pharmacology Group (SPG) which was continued as a PAMM sub-committee and renamed into: Drug Discovery Committee (DDC) [11]

A completely different compound, NSC-625492 was selected for its unique molecular structure being a bismuth analogue (Figure 4). The GI50 was low $(0.3 \mu \mathrm{M})$ with activity in many tumour types (colon, ovarian, non-small cell lung cancer and leukaemia; Figure 2). It was thought that it might form DNA adducts, because of its similarity to other heavy metals (e.g. platinum). Using this property, an assay using flameless atom absorption spectroscopy (FAAS) as used for cisplatin [24], was set up to determine its in vivo pharmacokinetics. The compound indeed showed interaction with DNA, but was not cross-resistant against cisplatin resistant cell lines and was active in P-glycoprotein expressing cell lines. Using a formulation of $10 \%$ DMA and arachis oil, the MTD was $30 \mathrm{mg} / \mathrm{kg}$ ( $8 \%$ weight loss), which was used to determine its plasma pharmacokinetics (Figure 5) and potential antitumor activity. NSC-625492 did not show a typical bell-shaped plasma profile curve, but the concentrations remained relatively constant over a 24-hr period, possibly indicating a lack of metabolism. Although sufficiently high plasma concentration (> GI50) were found, a long retention and no protein binding (in contrast to cisplatin), there was no in vivo activity against 
various tumour models. The development of the compound was therefore discontinued.

NSC-637828 also showed an interesting COMPARE negative profile (correlation coefficients < 0.625) with rifamycin and the nitrogen mustard CCNU (Lomustine; 1-(2-chloroethyl)-3-cyclohexyl-1-nitrosourea) being the highest. It was insoluble and a suspension could only be obtained in 10 \% DMA + arachis oil (but not in DMSO or ethanol), which showed acceptable toxicity (<10\%). Due to these properties an adequate HPLC method could not be established and drug sensitivity studies could not be completed. Therefore, the development of this compound was stopped.
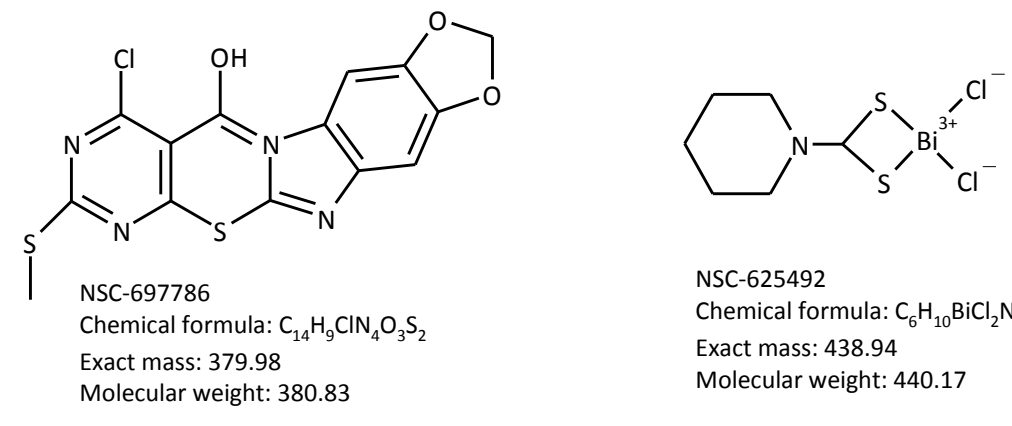

NSC-625492

Chemical formula: $\mathrm{C}_{6} \mathrm{H}_{10} \mathrm{BiCl}_{2} \mathrm{NS}_{2}$

Exact mass: 438.94

Molecular weight: 440.17
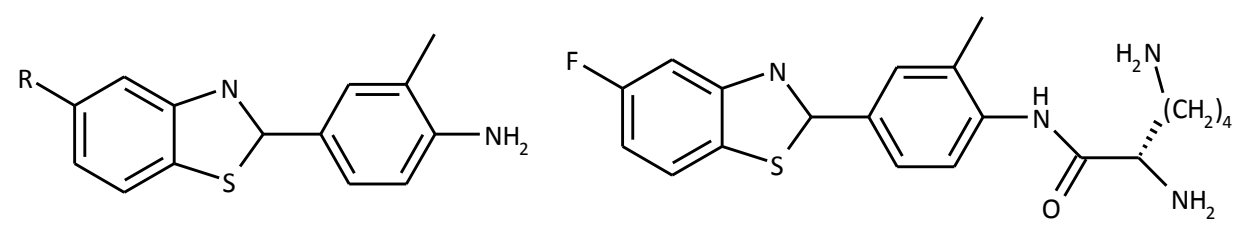

DF 203 (NSC 674495): $\mathrm{R}=\mathrm{H}$

$5 F 203$ (NSC 703786): $R=F$

Phortress (NSC 710305)

Chemical formula: $\mathrm{C}_{20} \mathrm{H}_{23} \mathrm{FN}_{4} \mathrm{OS}$

$2 \mathrm{HCl}$

Chemical formula 5F 203: $\mathrm{C}_{14} \mathrm{H}_{11 \mathrm{~F}} \mathrm{~N}_{2} \mathrm{~S}$

Exact mass: 258.06

Exact mass: 386.16

Molecular weight: 259.31

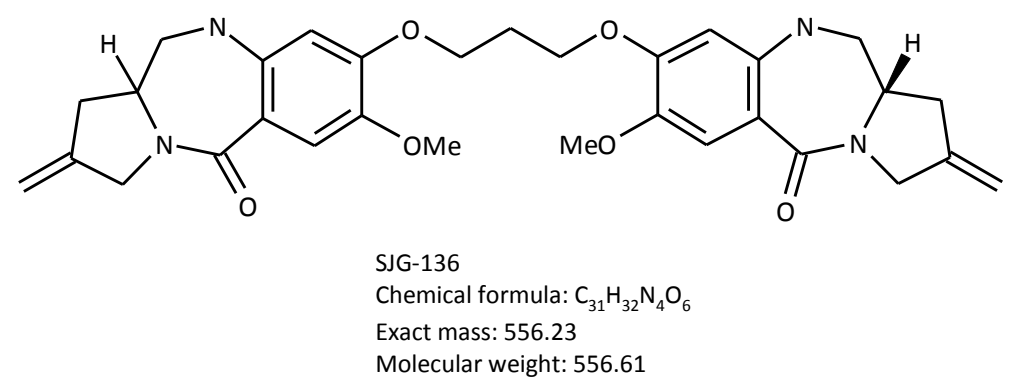

Figure 4. Structural formulas and some physico-chemical properties of several of the investigated compounds.

Two examples of drugs with completely different mechanisms of action are the combretastatin A-4 analogues and NSC 734237, a Paullone-like molecule. These two drugs were investigated in a collaborative effort of various PAMM laboratories and the $\mathrm{NCl}$ Drug Development and Target Analysis Branches. Combretastatin A-4 is a poorly soluble natural product and its more soluble metabolite combretastatin A-4 phosphate disrupts endothelial junctions of tumour blood vessels by preventing microtubule polymerisation in endothelial cells of tumour blood vessels; this resulted in tumour necrosis $[25,26]$. Various analogues (NSC736359, NSC736992, and NSC733436) with a high potency (nM- $\mu$ M range) were further analysed, but moderate antitumor activity was observed [27], possibly because under these conditions the density (size and number) of $\mathrm{CD} 31^{+}$blood vessels was not affected.

The Paullone-like molecule NSC 734237 is an isoindoloquinoxaline with low to sub $\mu \mathrm{M} I \mathrm{I}_{50}$ values [28] for CNS, colon, melanoma and breast cancer lines. However, the compound was quite insoluble $6 \%$ active drug in a liposomal formulation), but showed antitumor activity against a doxorubicin-resistant, oestrogen 
receptor negative human breast cancer xenograft MT-3/ADR with a reduction in both $C D 31^{+}$microvessel density and Ki-67. Hence the drug showed antivascular effects and cytotoxic activity, which are most likely due to inhibition of tubulin polymerisation and topoisomerase I, respectively. More water soluble analogues were investigated further, but did not improve the overall result. In the future, such compounds should optimally be investigated more extensively for their oral bioavailability and their formulation adapted.

\section{Concentration-time curve of NSC-625492 plasma of mice: total and free bismuth}

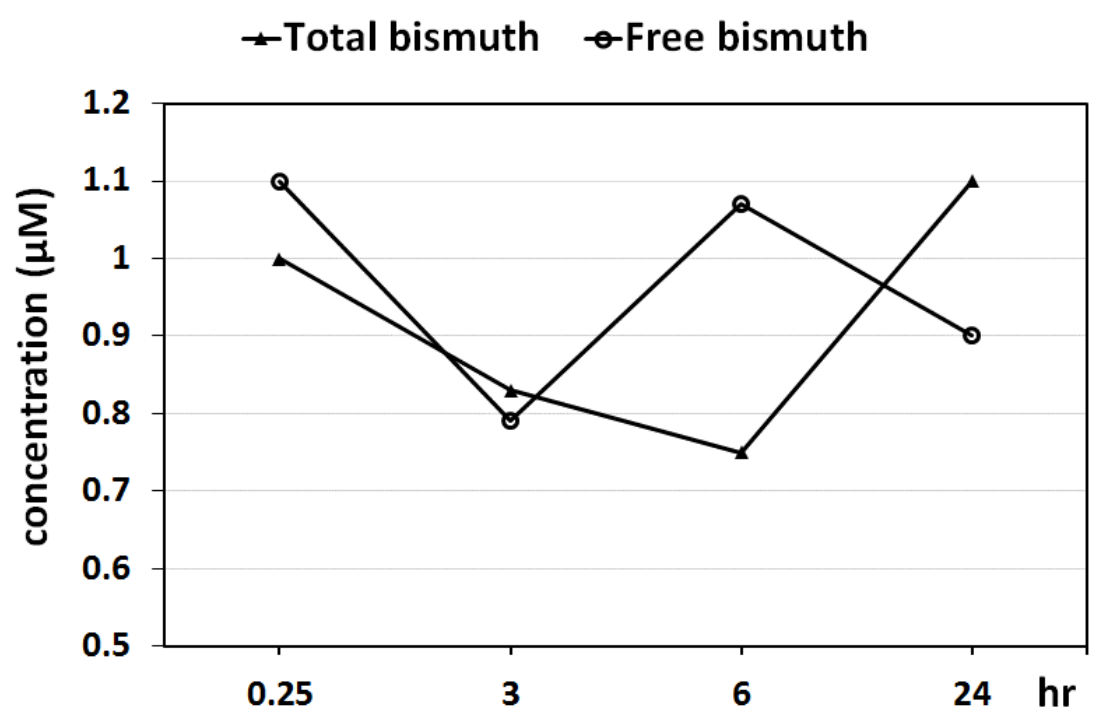

Figure 5. Concentration time curves of NSC-625492. Mice were injected with $30 \mathrm{mg} / \mathrm{kg}$ NSC-625492 in $10 \%$ DMA in arachis oil. For the pharmacokinetics study mice were sacrificed at $0.25,3,6$ and $24 \mathrm{~h}$ and blood was collected by heparinization to prepare plasma. Total bismuth was measured by mixing 1 volume of plasma with 5 volumes of triton/antifoam (1/1) and 4 volumes of $0.4 \mathrm{M} \mathrm{HCl}$, which was directly introduced into the AAS (Varian SpectrAA 300 Zeeman with certified Bi-lamp; $\lambda=306.8 \mathrm{~nm}$ ). Calibration lines were obtained with bismuth nitrate from 0.17 to $3 \mu \mathrm{M}$. Free bismuth (non-protein bound) was measured in the supernatant after deproteinization ( 1 volume of plasma mixed with 2 volumes of ethanol and put at $-20^{\circ} \mathrm{C}$ for $2 \mathrm{hr}$ followed by centrifugation for $10 \mathrm{~min}$ at $4000 \mathrm{~g}$ )

However, several compounds that showed an interesting profile in the $\mathrm{NCl}$-screen, were also successful at further evaluation, such as DRH-147 and Phortress. DRH-417, a pyrrolobenzodiazepine monomer acts by binding into the minor groove of DNA and was very potent in the $\mathrm{NCl} 60$-panel (mean IC50 $3 \mathrm{nM}$ ) and at subsequent testing by investigators of the European $\mathrm{NCl}$ compounds group [29]. It showed favourable pharmacokinetics (plasma peak levels of $171 \mathrm{nM}$, far above the Gl50 value) and interesting in vivo activity against several HTX models $(p<0.01)$. These data led to the development of SJG-136, a pyrrolobenzodiazepine dimer that went into a clinical Phase I study and Phase II studies in ovarian cancer and leukaemia [30].

Phortress (Figure 3 ) is a water-soluble benzothiazole prodrug of 5F-203, that is active (low nanomolar $\mathrm{Gl}_{50}$ ), and selective against breast, ovarian and lung cancer [31]. 5F-203 binds to cytoplasmic aryl hydrocarbon receptors, forming a complex that is translocated to the cellular nucleus, and subsequently binds to the cyp1a1 promoter [32,33]. This leads to an induction of the expression of cytochrome P450 1A1, responsible for metabolism of $5 \mathrm{~F}-203$ to a bio-reactive species that forms DNA-adducts. This unique mechanism of action, together with a good pharmacokinetic profile, led to further evaluation in Phase I clinical study [34], in which 14 out of 42 patients had stable disease. All together, these data show that the approach can lead to compounds with clinical activity. 


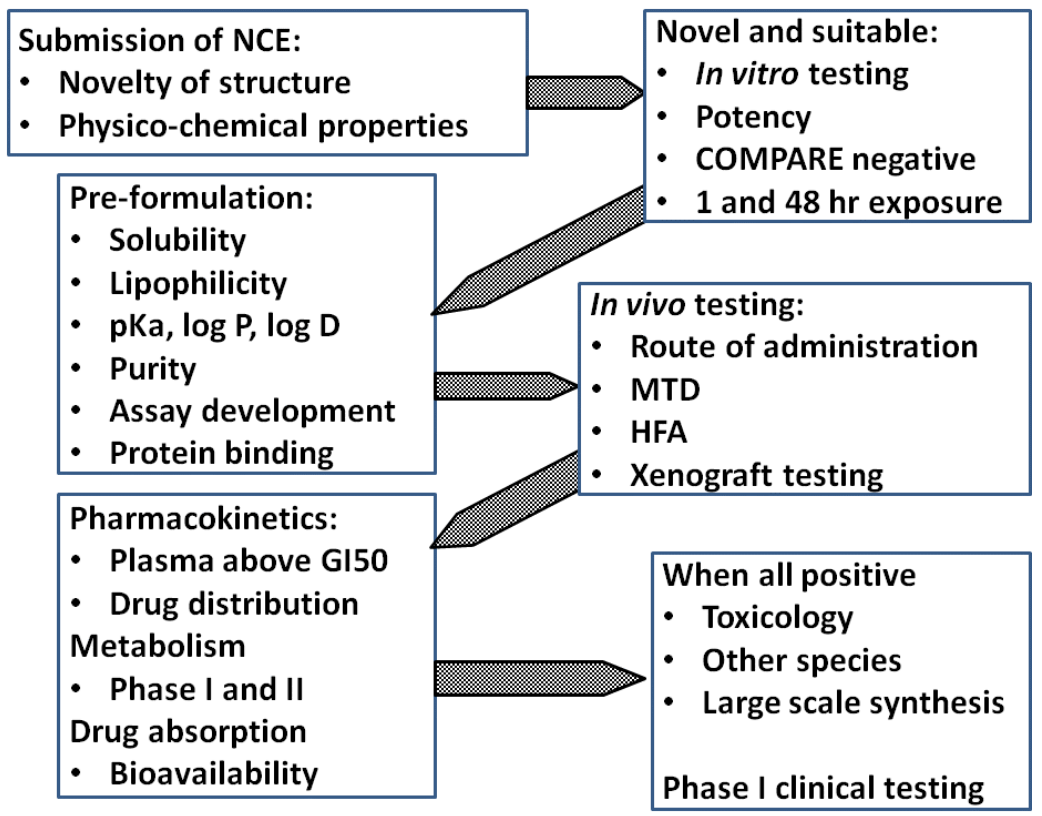

Figure 6. Flow chart showing the testing procedure and addition of novel parameters as outlined in the text. Each step can lead to elimination when not full-filling the criteria. NCE, new chemical entity; MTD, maximal tolerated dose; HFA, hollow fiber assay.

The first three examples show that despite initial enthusiasm about the drug sensitivity profile and COMPARE data, development had to be discontinued rapidly. Unfavourable physico-chemical properties, such as insolubility, made it impossible to perform adequate in vitro and in vivo studies and to set up suitable analytical assays. In addition to this and lack of in vivo activity, other reasons for discontinuation included instability, impurity, unavailability of material and insufficient bioavailability. A careful analysis of the mechanism of action helps to understand the success (DRH-147 and Phortress) but also enabled a systematic development of novel analogues. This was due to a successful scientific collaboration between different groups that provides a model for future drug development. Importantly the groups adhered to standard cellular pharmacology tools for testing [14].

\section{Conclusions}

The results of the pharmacologically directed approach clearly showed that a few simple procedures with small numbers of mice quickly allow discontinuing agents that were highly unlikely to have any antitumor activity. The process is outlined in the flow chart (Figure 6). The chart also shows some streamlining to optimize the process and eliminate agents with unsuitable pharmacological parameters in less than three months. Current approaches should put much more emphasis on physico-chemical properties such as solubility, pKa values, $\log P$ and $\log D$ values, protein binding and drug distribution. This serves two purposes, whether to discontinue development rapidly or when promising how to design an analogue with better properties. Regarding solubility, there are novel possibilities to use insoluble compounds with adequate solvents [35]. Using biomimetic approaches one would be able to gain insight in elimination constants, and likelihood of brain uptake [36]. Next to that, pharmacological evaluation should include Phase I (oxidation) and II (conjugation) drug metabolism which can currently easily being studied using isolated hepatocytes. Inclusion of such novel approaches would more rapidly predict whether a drug will have suitable pharmacological properties to proceed to the next step in development. 
Acknowledgements: The authors thank all members of the European $\mathrm{NCl}$ compounds group [10,11], consisting of investigators from the former EORTC-SPG and PTMG groups, the NCI, CRC and CRUK and the current EORTC-PAMM group and its DDC group.

\section{References}

[1] K. Tam. Estimating the "First in human" dose - a revisit with particular emphases in oncology drugs. ADMET \& DMPK 1 (2013) 63-75.

[2] M.R. Grever. Accelerating safe drug development: an ideal approach to approval. Hematology Am Soc Hematol Educ Program. 2013 (2013) 24-9.

[3] J.M. Bullock, A. Rahman, Q. Liu. Lessons learned: Dose selection of small molecule-targeted oncology drugs. Clin Cancer Res 22 (2016) 2630-8.

[4] J.W. Scannell, A. Blanckley, H. Boldon, B. Warrington. Diagnosing the decline in pharmaceutical R\&D efficiency. Nat Rev Drug Discov 11 (2012) 191-200.

[5] D. Buffery. The 2015 Oncology Drug Pipeline: Innovation Drives the Race to Cure Cancer. Am Health Drug Benefits 8 (2015) 216-22.

[6] P.B. Bach. Limits on Medicare's ability to control rising spending on cancer drugs. N Engl J Med. 360 (2009) 626-33.

[7] I. Kola, J. Landis. Can the pharmaceutical industry reduce attrition rates? Nat Rev Drug Discov. 3 (2004) 711-5.

[8] D. Lacombe, S. Burock, F. Meunier. Academia-industry partnerships: are we ready for new models of partnership?: the point of view of the EORTC, an academic clinical cancer research organisation. Eur J Cancer 49 (2013) 1-7.

[9] M.R. Grever, S.A. Schepartz, B.A. Chabner. The National Cancer Institute: Cancer drug discovery and development program. Semin Oncol 19 (1992) 622-638.

[10] H.R. Hendriks, A.S. Govaerts, I. Fichtner, A.D. Westwell, S. Hurtles, G.J. Peters, for the EORTC DDC group. Pharmacologically directed strategies in academic anticancer drug discovery based on the European NCl compounds initiative. Brit J Cancer 117 (2017) 195-202.

[11] G.J. Peters, E. Chatelut, A.K. Larsen, N. Zaffaroni, on behalf of PAMM. EORTC-related new drug discovery and development activities: role of the Pharmacology and Molecular Mechanisms Group. Eur J Cancer Suppl 10 (2012) 128-140.

[12] K.D. Paull, R.H. Shoemaker, L. Hodes, A. Monks, D.A. Scudiero, L. Rubinstein, J. Plowman, M.R. Boyd. Display and analysis of patterns of differential activity of drugs against human tumour cell lines: development of mean graph and COMPARE algorithm. J Nat/ Cancer Inst 81 (1989) 1088-1092.

[13] C.O. Leong, M. Suggitt, D.J. Swaine, M.C. Bibby, M.F.G. Stevens, T.D. Bradshaw. In vitro, in vivo, and in silico analyses of the antitumor activity of 2-(4-amino-3-methylpenyl)-5-fluorobenzothiazoles. Mol Cancer Ther 3 (2004) 1565-1575.

[14] P. Perego, G. Hempel, S. Linder, T.D. Bradshaw, A.K. Larsen, G.J. Peters, R.M. Phillips on behalf of the EORTC PAMM Group. Cellular pharmacology studies of anticancer agents: recommendations from the EORTC-PAMM group. Cancer Chemother Pharmacol 81 (2018) 427-441.

[15] M.G. Hollingshead, M.C. Alley, R.F. Camalier, B.J. Abbott, J.G. Mayo, L. Malspeis, M.R. Grever. In vivo cultivation of tumor cells in hollow fibers. Life Sci 57 (1995) 131-141.

[16] M.G. Hollingshead, J. Plowman, M. Alley, J. Mayo, E. Sausville. The hollow fiber assay. In Contributions to Oncology, Vol 54, Relevance of tumor models for anticancer drug development, (1999) H.H. Fiebig, A.M. Burger (eds),Karger: Basel pp. 109-120.

[17] R.M. Phillips, M.C. Bibby, J.A. Double. A critical appraisal of the predictive value of in vitro chemosensitivity testing. J Nat/ Cancer Inst 82 (2008) 1457-1468.

[18] I.V. Bijnsdorp, G.J. Peters. Hollow fiber assay. In Encyclopedia of Cancer, (2008) M. Schwab (ed). Springer Verlag: Berlin, Heidelberg, New York pp. 1404-1406. 
[19] J.I. Johnson, S. Decker, D. Zaharevitz, L.V. Rubinstein, J.M. Venditti, S. Schepartz, S. Kalyandrug, M. Christian, S. Arbuck, M. Hollingshead, E.A. Sausville. Relationships between drug activity in $\mathrm{NCl}$ preclinical in vitro and in vivo models and early clinical trials. Br J Cancer 84 (2001) 1424-1431.

[20] S.L. Holbeck. Update on NCl in vitro drug screen utilities. Eur J Cancer 40 (2004) 785-793.

[21] H.H.J. Backus, H.M. Pinedo, D. Wouters, J.M. Padron, N. Molders, C.L. Van der Wilt, C.J. Van Groeningen, G. Jansen, G.J. Peters. Folate depletion increases sensitivity of solid tumor cell lines to 5fluorouracil and antifolates. Int. J. Cancer 87 (2000) 771-778.

[22] G.J. Peters, S.L. Sharma, E. Laurensse, H.M. Pinedo. Inhibition of pyrimidine de novo synthesis by DUP-785 (NSC 368390). Invest. New Drugs 5 (1987) 235-244.

[23] I.V. Bijnsdorp, E.M. Comijn, J.M. Padron, W.H. Gmeiner, G.J. Peters. Mechanisms of action of FdUMP[10]; Metabolite activation and thymidylate synthase inhibition. Oncol. Rep. 18 (2007) 287291.

[24] C.J.A. Van Moorsel, H.M. Pinedo, G. Veerman, A.M. Bergman, C.M. Kuiper, J.B. Vermorken, W.J.F. Van der Vijgh, G.J. Peters. Mechanisms of synergism between cisplatin and gemcitabine in ovarian and non-small cell lung cancer cell lines. Brit. J. Cancer 35 (1999) 808-814.

[25] G.G. Dark, S.A. Hill, V.E. Prise, G.M. Tozer, G.R. Pettit, D.J. Chaplin. Combretastatin A-4, an agent that displays potent and selective toxicity toward tumor vasculature. Cancer Res 57 (1997) 1829-1834.

[26] G.M. Tozer, C. Kanthou, C.S. Parkins, S.A. Hill. The biology of the combretastatins as tumour vascular targeting agents. Int J Exp Pathol 83 (2002) 21-38.

[27] K. Bonezzi, G. Taraboletti, P. Borsotti, F. Bellina, R. Rossi, R. Giavazzi. Vascular disrupting activity of tubulin-binding 1,5-diaryl-1H-imidazoles. J Med Chem 52 (2009) 7906-7910.

[28] P. Diana, A. Martorana, P. Barraja, A. Montalbano, G. Dattolo, G. Cirrincione, F. Dall'acqua, A. Salvador, D. Vedaldi, G. Basso, G. Viola. Isoindolo[2,1-a]quinoxaline derivatives, novel potent antitumor agents with dual inhibition of tubulin polymerization and topoisomerase I. J Med Chem $\mathbf{5 1}$ (2008) 2387-2399.

[29] A.M. Burger, P.M. Loadman, D.E. Thurston, R. Schultz, H.H. Fiebig, M.C. Bibby. Preclinical pharmacology of the pyrrolobenzodiazepine (PBD) monomer DRH-417 (NSC 709119). J Chemother 19 (2007) 66-78.

[30] J. Mantaj, P.J.M. Jackson, K. Rahman, D.E. Thurston. From anthramycin to pyrrolobenzodiazepines (PDB)- containing antibody conjugates (ADCs). Angew Chem Int Ed Engl 56 (2017) 462-488.

[31] I. Fichtner, A. Monks, C. Hose, M.F. Stevens, T.D. Bradshaw. The experimental antitumor agents Phortress and Doxorubicin are equiactive against human-derived breast carcinoma xenograft models. Breast Cancer Res Treat 87 (2004) 97-107.

[32] T.D. Bradshaw, A.D. Westwell. The development of the antitumour benzothiazole prodrug, Phortress, as a clinical candidate. Curr Med Chem 11 (2004) 1009-1021.

[33] T.D. Bradshaw. Phortress: the smart antitumour agent which induces its own metabolism. Pharm J 284 (2010) 23-24.

[34] M. Seckl, N. Cresti, A. Boddy, R. Phillips, F. Chapman, H. Calvert, L. Robson, R. Plummer. A Cancer Research UK Phase I trial of Phortress (novel antitumour benzothiazole) given intravenously in consecutive 21 day cycles with treatment on Day 1 of each cycle. In: Proc $8^{\text {th }}$ NCRI Cancer Conference, 4-7 November 2012, Liverpool, UK. Abstract LB79.

[35] A. Avdreef. Suggested Improvements for Measurement of Equilibrium Solubility-pH of Ionizable Drugs. ADMET \& DMPK 3 (2015) 84-109.

[36] K. Valko, S.P. Teague, C. Pidgeon. In vitro membrane binding and protein binding (IAM MB/PB technology) to estimate in vivo distribution: applications in early drug discovery. ADMET \& DMPK 5 (2017) 14-38. 